Article

\title{
Classical Guitar Study as Creativity Training: Potential Benefits for Managers and Entrepreneurs
}

\section{Jonathan Gangi $(\mathbb{D}$}

School of Music, College of Arts \& Architecture, The Pennsylvania State University, University Park, PA 16802, USA; jjg27@psu.edu

Received: 12 July 2018; Accepted: 19 September 2018; Published: 25 September 2018

check for updates

\begin{abstract}
Divergent thinking ability, as an aspect of creativity, seems valuable to managers and entrepreneurs as they employ the tools of creative problem-solving and innovative thinking in pursuit of business success. Musical study in general, and classical guitar study to a greater degree, has the potential to improve divergent thinking and creative problem-solving abilities. As such, I suggest that utilizing classical guitar study as a creativity training tool may benefit entrepreneurs and managers within a variety of industries.
\end{abstract}

Keywords: classical guitar study; divergent thinking; creativity training; creative problem-solving; innovation; entrepreneurship; management

\section{Introduction}

The arts provide many benefits to humanity, such as the physical use of the hands and body and using the whole mind, among many others, and are sources of alternate ways to learn and solve problems [1]. This is not to say the arts are the only disciplines providing these types of benefits, but rather they engage the mind and body in specific ways that may not be readily observable to those lacking a deep knowledge of a particular art form. Classical guitar study, if approached in a particular way, has the potential to foster creative thinking, thus any person interested in classical guitar study may become more creative by engaging with this method. In this conceptual paper, I urge managers and entrepreneurs to consider the long-term benefits of classical guitar study, as it may help them to think more creatively in their work environments. There are many ways to develop creative thinking, of course, and I am not suggesting that classical guitar study is the only way, or the best way. Many managers and entrepreneurs may not find music or guitar appealing as an area of study or long-term hobby. I am simply illustrating, for those that find it attractive, how a particular approach to classical guitar study presents a rich environment for creativity training.

Entrepreneurs and managers need creativity to be successful in the tasks of creating, communicating, and exchanging value with a variety of stakeholders, suppliers, distributers, and customers. Some scholars believe that entrepreneurship involves creating and exchanging forms of value [2-4]. I agree with this characterization of what entrepreneurs do, and for this article entrepreneurship refers to creating and exchanging value. For this exchange to take place, communicating value must take place as well. Managers can also do these same activities. When I refer to managers, I mean those in positions that require making executive decisions. I view managers and entrepreneurs as leaders who make executive decisions and work in problem-spaces of uncertainty, although entrepreneurs deal with uncertainty more so than managers [5]. Nevertheless, managers and entrepreneurs deal with, to varying degrees, bearing uncertainty, seeking profit in a variety of forms, and making ultimate decisions [6]. They are part of the super-creative core, the type of knowledge-worker that must determine their own tasks and the tasks of others [7]. As such, creativity is crucial to their daily tasks, their own success and that of their employees and organizations [8]. 
Innovation pertains to creating novelty in a variety of forms that is useful in some manner [9]. Innovation is the tool of entrepreneurs, and certainly involves creativity throughout the process [10]. Managers who implement innovative new products, services and initiatives within an existing organization seem to operate in a similar fashion to entrepreneurs, and are often referred to as intrapreneurs. When something novel is introduced, by a manager or entrepreneur, the problem-space becomes one of uncertainty and unknown variables [5]. This too requires creativity on the part of executive decision-makers, as they seek to problem-solve in an innovative, or novel and useful way. Although this article is not about entrepreneurship, innovation, or management, per se, these conceptualizations and categorizations point out that managers and entrepreneurs certainly need to be creative to be successful. This article is about classical guitar training and the similarities between professional classical guitarists, managers, and entrepreneurs, as the following section explores.

\section{Cognitive Function Similarities in Guitarists, Managers and Entrepreneurs}

Classical guitarists may not view themselves as managers or entrepreneurs, and managers and entrepreneurs may not consider themselves to have much in common with guitarists or believe that guitar training has the potential to benefit their managerial and entrepreneurial activities. In actuality, however, these two seemingly disparate groups have similar cognitive operations. Likewise, sustained classical guitar practice may be an invaluable resource for creativity training and divergent thinking development. This section of the article reveals how professional classical guitarists act managerially and entrepreneurially. The intention is to help business professionals in non-arts fields recognize the similarities that exist between themselves and classical guitar professionals, and vice versa. Hopefully, managers and entrepreneurs of all kinds (arts and non-arts) will see the similarities, feel a sense of solidarity and camaraderie, and become motivated to begin the process of classical guitar study as an arena for creativity training and life-long enjoyment.

Successful professional classical guitarists think and behave like managers and entrepreneurs. How so? Two articles from the business literature describe five managerial mind-sets and five entrepreneurial mind-sets, as spin-off concepts based upon psychologist William Gardner's well known 'Five Minds.' I chose to cite these two particular sources because, when combined, these ten 'minds' illustrate the similarities between the cognitive functioning of successful professional guitarists, business managers, and entrepreneurs.

First, from the management literature [11], we see five perspectives of management practice:

1. Managing self: the reflective (thinking abstractly) mind-set;

2. Managing organizations: the analytic mindset;

3. Managing context: the worldly mind-set;

4. Managing relationships: the collaborative mind-set;

5. Managing change: the action mind-set.

Secondly, from the entrepreneurship literature come five entrepreneurial minds [12], each pertaining to cognitive skills that successful entrepreneurs possess and utilize:

1. The Opportunity Recognizing Mind: the recognition of opportunity is essential to entrepreneurship;

2. The Designing Mind: this mind defines the need to combine disparate ideas, people, or physical objects in novel ways that appeal to others;

3. The Risk Managing Mind: the ability to manage risk refers both to the ability, emotionally, to manage perceived risk and the ability to reduce actual risk through specific actions;

4. The Resilient Mind: successful entrepreneurs develop resilience only through multiple real-world failures;

5. The Effectuating Mind: this mind is about taking action in a world of uncertain and often unpredictable outcomes. 
Professional guitarists think abstractly about how the instrument works, how their physiology relates to the instrument, and in making choices about how to physically play the notes and decisions about the musical expression within the interpretation of the piece. The end result of thinking abstractly is to inform practical doing as it relates to the self, the instrument, and the music. Further, reflection (thinking abstractly), collaboration, organization, context, and taking action are important to guitarists in their professional practice of performing and teaching.

In preparation for performing, guitarists need skill in recognizing opportunities for brilliant technical and musical choices within a piece, opportunities for playing new repertoire or collaborating with significant composers or performers, and innovative performance venue opportunities. Design is important when arranging or composing new works for guitar, as well as identifying how to physically perform the music, musical patterns, and shaping a long-term career trajectory. Guitarists must manage and mitigate risk, remain resilient, and take action in the face of uncertainty when striving to acquire and maintain professional levels of teaching, performing, arranging, and composing with the guitar.

Professional guitarists think and act like managers and entrepreneurs by making executive decisions concerning repertoire, audience engagement strategies, musical interpretation, pedagogical philosophy and style, and the entire scope of their career. As primarily solo performers, classical guitarists must operate autonomously and direct themselves, rather than relying on a leader like ensemble players who are directed by a conductor. This requires guitarists to make executive decisions regarding the allocation of resources, both technically and musically, while adapting in real time by monitoring results using feedback loops in practice and performance. Guitarists also need to create long-range plans for developing technically, musically, and pedagogically with an orientation towards their career as a whole.

Three praxeological dimensions of entrepreneurship are profit-seeking, uncertainty-bearing, and ultimate decision-making [6]. Professional guitarists seek multiple forms of profit, visible in the expectation of technical and musical profit from practicing and pecuniary profit from teaching and performing. Artists also seek profit in the form of intrinsic satisfaction from personal achievement, positively affecting others through art, and being valued by audiences and students as accomplished performers and pedagogues.

Guitarists similarly bear uncertainty as a matter of course. Traditional employment routes are challenging and require guitarists to create their own careers. Every concert requires dealing with the possibility of failing to deliver a compelling performance, potentially leading to decreased future performances. Likewise, ultimate decision-making is inherent in repertoire selection, solutions for physically performing the repertoire, student recruitment, concert bookings, and the assembly of a fiscally solvent career. These decisions are managerial and entrepreneurial in nature and require creative problem-solving and divergent thinking.

How is this relevant to managers and entrepreneurs who are not professional musicians? I am not suggesting that managers and entrepreneurs must become professional classical guitarists in order to reap the benefits of classical guitar study. I am merely providing an inside look into an artistic process, highlighting the similarities between guitarists and non-musicians and encouraging managers and entrepreneurs of all kinds to begin a life-long journey of discovery and pleasure playing the classical guitar. Through deliberate and sustained classical guitar practice, executives could develop a greater capacity for the type of creative thinking that is vital for managers and entrepreneurs as they seek to innovatively create and exchange value and effectively run organizations.

\section{Divergent Thinking Defined}

So, what is divergent thinking? Since the middle of the 20th century, divergent thinking has been considered a primary cognitive component of creativity $[13,14]$. Scholars Runco and Acar point out that:

"Divergent thinking is not the same as creative thinking. Divergent thinking often leads to originality, and originality is the central feature of creativity, but someone can do well on 
a test of divergent thinking and never actually perform in a creative fashion ... There is [however], great value in the concept of divergent thinking. Much of the research focuses on divergent thinking tests, and their reliability and validity, but additional research tells us more broadly how divergent thinking ... is associated with problem-solving, ideation, and creative potential." [15]

Researchers Gibson, et al. explain that:

"Divergent thinking is distinguished from convergent thinking, which is defined by a narrowing of possible responses to reach the correct solutions. In contrast, divergent thinking involves flexible ideation to generate many responses to open-ended and multifaceted problems. Convergent thinking works best with well-defined problems that have a clearly defined response, while divergent thinking is best suited for poorly defined or unstructured problems ... Since Guilford's seminal contribution to the study of creativity, divergent thinking has remained a conceptually, internally, and externally valid element of the creative process." [16]

According to Guilford, divergent thinking provides the foundation for creative production because it requires ideational searching without directional boundaries [14]. He identified four aspects of divergent thinking [14,17]:

1. fluency - the ability to produce a great number of ideas or problem solutions in a short period of time;

2. flexibility - the ability to simultaneously propose a variety of approaches to a specific problem;

3. originality-the ability to produce new, original ideas; and

4. elaboration - the ability to systematize and organize the details of an idea and carry it out.

\section{Research Suggests Musicians May Be Better Divergent Thinkers}

Cognitive science provides compelling research supporting the assertion that guitar training may develop divergent thinking. One publication in particular details an experiment designed to test creative thinking in musicians and non-musicians. The authors summarize their work, stating:

"Performing artists are implicitly assumed to have greater creative potential than the general population...Musicians are a particularly relevant population to study because of their intensive, long-term training that may have a significant impact on neural circuits that are associated with creativity ... Therefore, it was logical to ask if trained musicians might show increased creativity in non-musical tasks as well." [16]

Results of the study are as follows:

“... we found evidence for increased creativity in trained musicians... These results suggest that musicians have increased convergent and divergent thinking compared with non-musicians ... It is possible that music training influences brain organization such that the resulting cognitive system is prone to divergent thinking." [16]

This study supports my suggestion that a particular approach to classical guitar training has the potential to develop divergent thinking capacity. Although participants were musicians who played piano, strings, and woodwind instruments, it seems logical that this would also be true of classical guitarists. The particular approach to classical guitar training explained in the following section may develop incredibly high levels of divergent thinking skill due to the idiosyncrasies of the guitar. Classical guitarists have unique challenges presented to them by their instrument that musicians playing other instruments do not encounter. For example, although the piano is a complex instrument, fingering choices are simplified because each note on the musical staff can only be played in one specific location on the keyboard. This reduces the need for, and the instrumental constraints 
that foster, divergent thinking skill. On the guitar, however, there are three or four string and fret location options for any given note. Thus, when compared to other musical instruments, the classical guitar may offer the most fertile ground for divergent thinking training.

\section{How Classical Guitar Training May Develop Divergent Thinking Expertise}

The creative decision-making process of a particular approach to classical guitar training utilizes Guilford's aspects of divergent thinking. Many guitarists do not possess adequate knowledge of the fretboard and instead rely on rote learning, resulting in difficulty recognizing fingering options and changing to a better solution. Therefore, this section presupposes that guitarists are working towards or possess the following prerequisites of thinking divergently with the instrument, as defined by Christopher Berg, a prominent sage of classical guitar performance, scholarship, and pedagogy:

1. an expert knowledge of the fretboard;

2. an accurate perception of personal capabilities and limitations, including distinguishing between concrete limitations versus undeveloped skills;

3. a clear idea of musical problems to be solved;

4. a sense of what fingerings work well at slow tempos, but not at tempo, versus a sense of what fingering will work at tempo; and

5. a heightened sense of the instrument's technical capabilities [18].

When guitarists learn a musical work, they must determine how to physically perform the piece, a process referred to as "fingering". Sherrod defines fingering as:

“... the exact, well-planned, and deliberate designation of fingers to a given passage. The primary consideration for any guitarist is an authentic and artistic performance of the music. The methodical and meticulous choice of fingers is of utmost importance in accomplishing this task." [19]

Both the right and left hands, as used in classical style guitar playing, require fingering choices. Regarding this, Yates states:

"[Fingering choices are impacted by the] melodic and harmonic context and the compromise between musical effect and technical expediency. [Choices are also impacted] by the physical limits of the instrument, and by the facility of the player, noting that results in performance will likely reflect the intentions of the player as much as the implications of the fingerings themselves." [20]

The task of creating effective fingering solutions on the guitar, as highlighted by these authors, necessitates implementing each aspect of divergent thinking (fluency, flexibility, originality, elaboration) to navigate successfully through complex musical textures. For example, the guitarist is required to be fluent, or produce a great number of ideas or problem solutions in a short amount of time when learning a new piece of music. The problems presented involve musical issues, such as melodic and harmonic context and musical effect, as well as technical (i.e., what is required of the fingers physically).

During this time of fluency, the guitarist also must demonstrate flexibility, by generating a variety of fingering choices for the specific problem area. This includes being original with ways of playing the passage, because often the fingerings included in the score are the solutions that worked best for a specific individual, and are typically intended as suggestions. Finally, the guitarist must be able to elaborate, or organize and systematize the fingering ideas and solutions, and physically test each to determine which solution best satisfies both the technical and aesthetic demands of the work. Recombination, the activity of taking fragments of different ideas and combining them to produce a brilliant and unexpected result, is another important skill to use during the elaboration process [18]. 
A guitarist's need for high levels of divergent thinking is revealed by examining how the fretboard works. For example, many notes can be played on four different frets and strings, despite the fact that they are the same pitch and are identically notated. The note E, in the top space of the treble clef, could be played on the open first string, or the fifth fret of the second string, or the ninth fret of the third string, or the fourteenth fret of the fourth string. The choice depends on the musical texture, melodic and harmonic context, musical effect, desired tone color, and right and left hand technical requirements.

The Gigue of J.S. Bach's Lute Suite BWV 1006a provides fertile ground for enlivening the divergent thinking process. Guitarists must move cognitively through each aspect of divergent thinking when engaging with the notes of measure ten, shown in Figure 1.

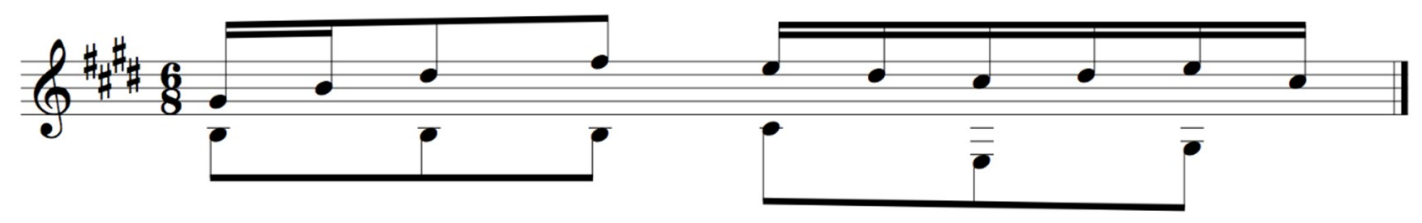

Figure 1. Gigue, measure 10, of J.S. Bach's Lute Suite BWV 1006a.

First, they must be fluent, or produce a great number of ideas or problem solutions, and demonstrate flexibility, by generating a variety of fingering choices for the specific problem area. Figures 2-8 represent seven possible combinations of strings that theoretically would produce the pitches Bach wrote in measure ten. Six of the presented options are original to the author, while the seventh is the suggestion of an editor [21]. Seven examples may seem excessive, but are included because they represent the full scope of possible locations to play the notes in Figure 1, and serve to emphasize my point that the guitar provides an almost overwhelming amount of possibilities, perhaps more so than other instruments. In each example the circled numbers represent the guitar string that could produce the given pitch (by left hand fingers pressing appropriate strings down to appropriate frets), and the letters represent the right hand fingers that pluck each note ( $p=$ thumb, $i=$ index, $m=$ middle, $a=$ ring). These examples show how guitarists elaborate by systematizing the fingering solutions and physically testing each to determine which option best satisfies the technical and aesthetic demands of the music and is doable within the constraints of an individual's unique physiology.

All of the following examples are theoretically possible, yet some are physically impossible. The more absurd options, since they are physically impossible, are Figures 2-5.

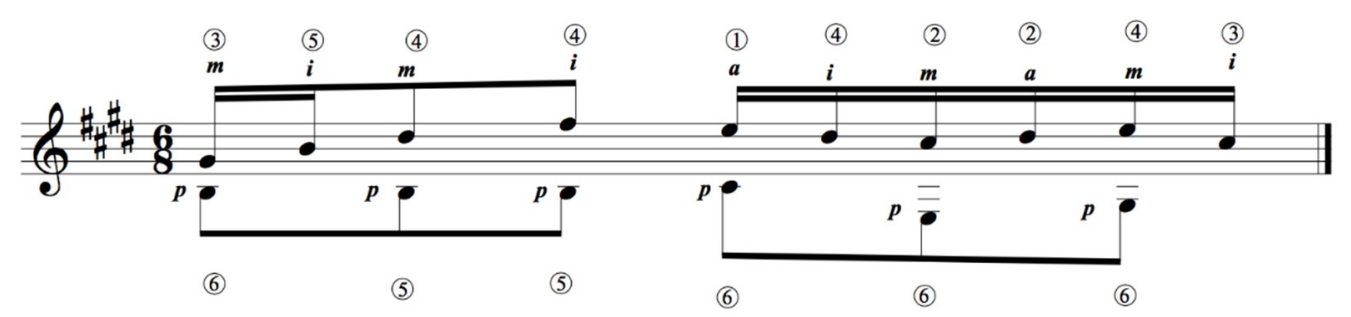

Figure 2. Physically Impossible.

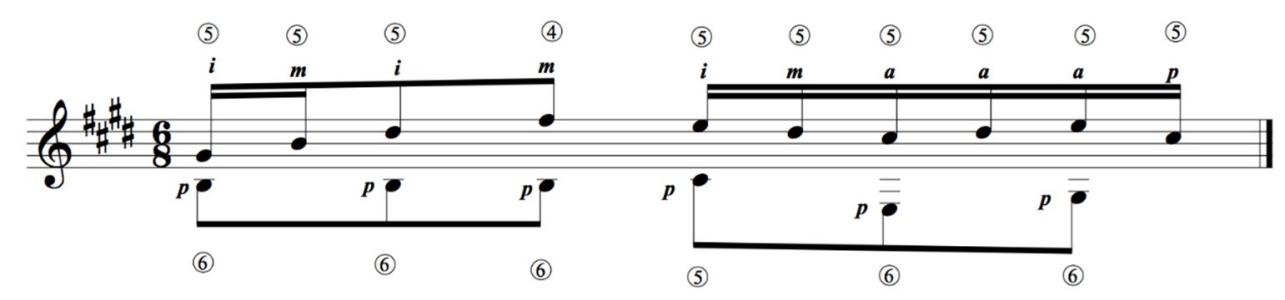

Figure 3. Physically Impossible. 


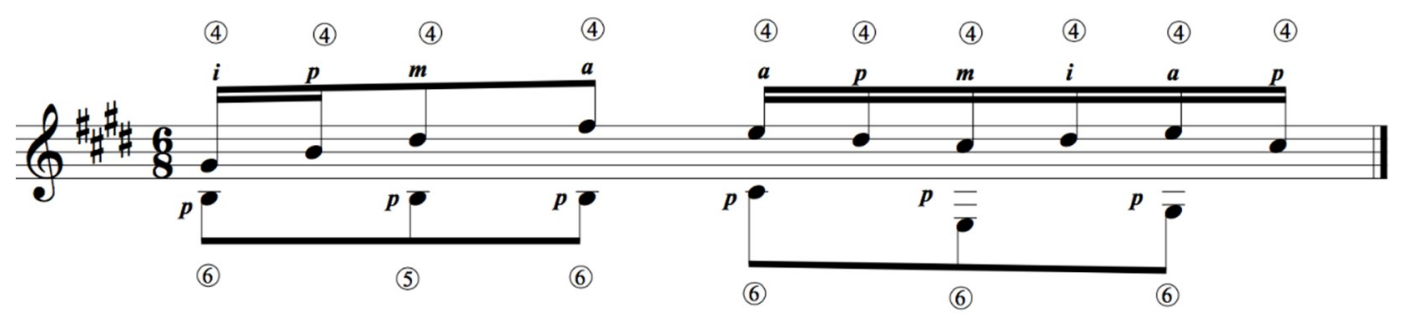

Figure 4. Physically Impossible.

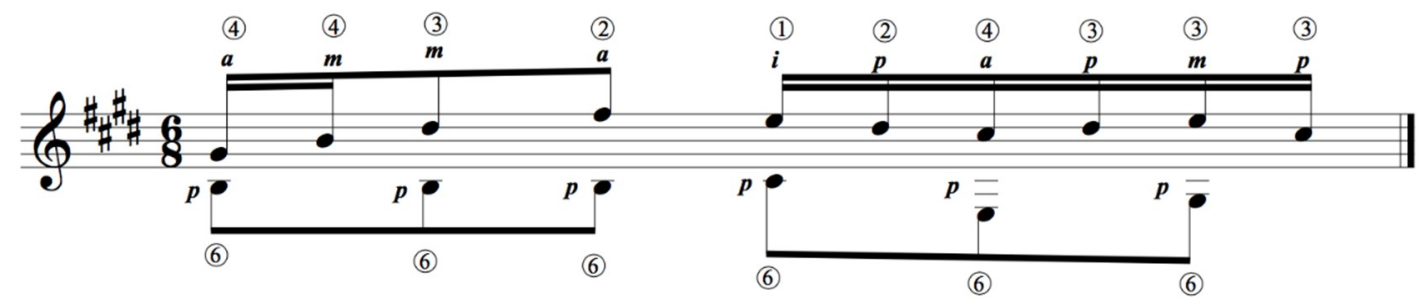

Figure 5. Physically Impossible.

Figures 6-8 are the best remaining choices. Of these, Figures 7 and 8 are better than 6 , because the musical result of Figure 6 would be more detached and choppy in sound, or less connected and lyrical.

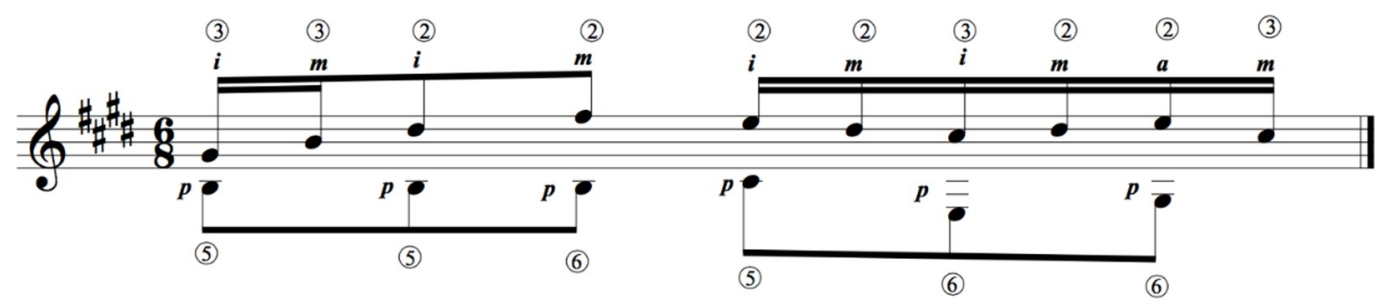

Figure 6. Viable Solution.

For the remaining examples, the choice between 7 and 8 is made by context, preference, physiology, and aesthetic taste. My preference is Figure 7, while others would perhaps choose Figure 8.

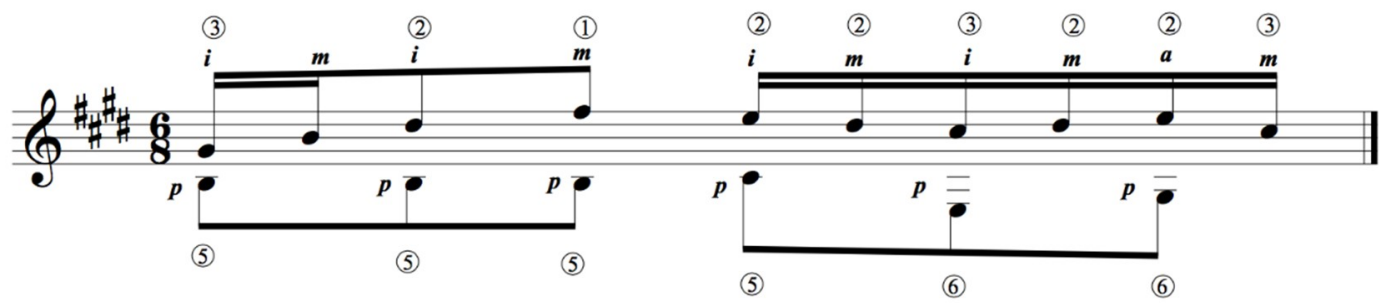

Figure 7. My Preference.

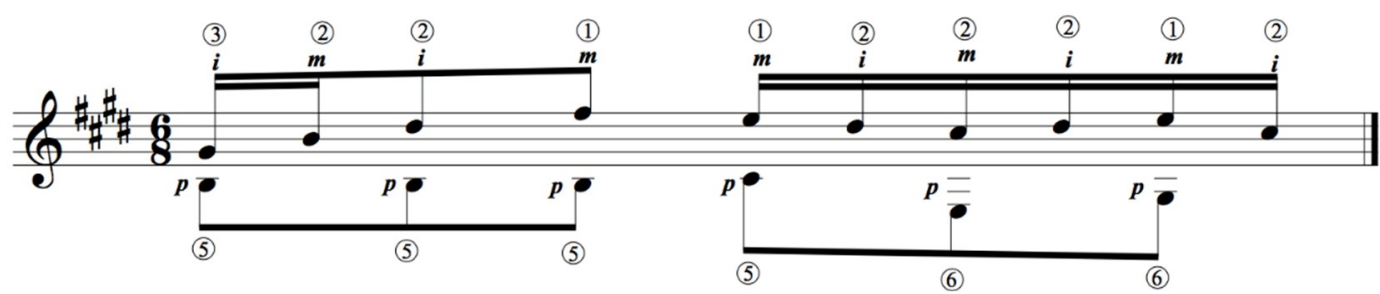

Figure 8. Good Solution.

Thus far, choices have been made based solely upon which strings to use to play the notes and illustrates how this creative decision-making process necessitates incorporating the full range of cognitive activity required to think divergently, as presented previously. Added to this, the guitarist 
must make choices about which finger to use for each note on each string for each hand (the examples provided above do not include left hand fingering choices, rather they only include string choices for producing each note). The cumulative effect reveals an incredible amount of possibilities for playing only one measure of contrapuntal music on the guitar. Learning an entire musical work using this creative problem-solving process provides numerous opportunities for creativity training and the development of divergent thinking expertise.

\section{Divergent Thinking Expertise Applied to Management \& Entrepreneurship}

My thesis is that classical guitarists have the potential to develop high levels of divergent thinking capacity through a particular learning process, as previously described. Simply due to the nature of their instrument, classical guitarists can develop core capacities and innate advantages for creativity and problem-solving. If this invaluable skill is applied to other domains, guitar training can be utilized as a method for creative success in other contexts, such as managerial and entrepreneurial action within the business environment. How is this skill applied? Through the sustained and deliberate practice of the techniques of expert entrepreneurs.

Innovation involves creating novel and useful combinations of means, or resources. Entrepreneurship involves creating and exchanging forms of value by interacting with a variety of stakeholders, such as partners and customers. Intrapreneurs and managers must be innovative in developing and exchanging new forms of value while maintaining and sustaining organizational success. Expert entrepreneurs continuously think about what they can do with their resources, what else they can do, and what commitments can be made with others who can provide more resources and possibilities [22].

Saras Sarasvathy's research shows us how expert entrepreneurs creatively transform resources into opportunities [22], and provides eight transformation types:

1. Deleting/supplementing —subtracting from or adding to an existing offering;

2. Composing/decomposing-reorganizing material that is already there, decomposing and recomposing it;

3. Exaptation-transforming existing artefacts by converting them to new uses;

4. Re-weighting -increasing or decreasing the emphasis of features or attributes;

5. Manipulation-inverting, mirroring, twisting, turning an idea or artefact inside out;

6. Deformation-deliberately deforming the original idea or concept, analogous to melody deformation in jazz;

7. Localization/regionalization/globalization—changing the scope of the market by proposing smaller or larger markets;

8. Ad hoc associating-drawing on prior experiences and memory by associating the current venture with some previous problem or opportunity.

The creative process of these transformation types is very similar to the creative problem-solving process used in classical guitar study. Solving fingering problems in a musical work involves deleting/supplementing by subtracting or adding to the existing fingering solutions that are typically printed in the musical score by an editor. Composing/decomposing, manipulation, deformation, and re-weighting are utilized very often as well when making choices for fingerings and musical interpretation. Even ad hoc associating is involved by drawing upon prior experience and memory of fingering solutions learned when studying previous pieces of music. Expert guitarists think about what can be done to solve fingering problems in a musical passage, and what else can be done. This is the particular manner in which the cognitive processing of classical guitarists, as described previously, is identical to innovative managers and entrepreneurs.

These transformation types are tools and techniques for creating valuable combinations of resources. Knowing the transformation types is only the beginning of successfully transforming means into valuable ideas. The challenge is developing the divergent thinking expertise that is necessary 
for better results from creativity training exercises. Divergent thinking expertise seems crucial to generating creative business ideas. Business school training develops analytical and predictive skill, but not necessarily divergent thinking expertise. There are many wonderful pedagogical approaches to entrepreneurship education that provide creativity exercises, yet many students, teachers, and professionals still struggle to produce creative ideas. Sustained and deliberate classical guitar study can be a creativity training opportunity and one possible solution to the challenge of generating creative and valuable ideas.

Managers and entrepreneurs who are already creative and exhibit expert divergent thinking abilities may still benefit from classical guitar study. One research study in particular shows that preoccupation with reward reduces creativity:

"Explicitly contracting to do an activity in order to obtain a reward leads to lower levels of creativity than contracting to do the activity for no reward, or simply being presented with the task, or being presented with the task and a subsequent reward. The implications of this finding are intriguing. It may be that commissioned work will, in general, be less creative than work that is done out of pure interest. And, within an ongoing work organization or classroom setting, it may be that tying specific rewards to specific tasks chosen by workers and students will be less conducive to creativity than simply allowing choice of activities without specific pay-offs attached to each task." [23]

If managers and entrepreneurs are too focused on the reward (i.e., financial profits, achieving the organizational mission, etc.), this may reduce their creativity when solving problems and generating ideas for products, services, initiatives, and programs. Training the brain to generate original solutions during classical guitar study could be utilized as a way to learn to be creative as an end in itself, rather than seeking a reward. Conceptually, it seems that managers and entrepreneurs could transfer this ability from classical guitar study into their professional domain. Many artists, including classical guitarists as mentioned previously, engage in their art form for the intrinsic satisfaction they derive from it, not necessarily for any particular reward, and often in spite of the knowledge that they may struggle to earn enough money to make a living. If entrepreneurs and managers and learn to do the same, perhaps it will allow them to become even more creative.

\section{Summary}

Cognitive science research suggests that musicians may possess distinct advantages in divergent thinking tasks. Divergent thinking skill may result from utilizing a particular method of classical guitar study. Thus, anyone who is interested in creativity training and classical guitar study could develop divergent thinking expertise through long-term, focused practice. In this article I have presented conceptual evidence to support my suggestion that classical guitar study may benefit and enhance the creativity and innovative behavior of managers and entrepreneurs. A future research goal is to empirically test this hypothesis.

Funding: This research received no external funding.

Acknowledgments: The author is grateful to the reviewers and editors for their valuable feedback and helpful suggestions.

Conflicts of Interest: The author declares no conflict of interest.

\section{References and Note}

1. Dissanayake, E. The Universality of the Arts in Human Life. In Understanding the Arts and Creative Sector in the United States; Cherbo, J.M., Stewart, R.A., Wyszomirski, M.J., Eds.; Rutgers University Press: New Brunswick, NJ, USA, 2008; pp. 61-74.

2. Gartner, W.B. Who is an entrepreneur? Is the wrong question. Am. J. Small Bus. 1988, 12, 11-32. [CrossRef]

3. Gartner, W.B. Arts entrepreneurship: Scope, practice and community. Artivate J. Entrep. Arts 2015, 4, 3-6. 
4. Mishra, C.S.; Zachary, R.K. The Theory of Entrepreneurship: Creating and Sustaining Entrepreneurial Value; Palgrave Macmillan: Basingstoke, UK, 2014.

5. Sarasvathy, S.D. Effectuation: Elements of Entrepreneurial Expertise; Edward Elgar: Cheltenham, UK, 2008.

6. Giménez-Roche, G.A. A Socially Situated Praxeological Approach to Entrepreneurship. J. Entrep. 2011, 20, 159. [CrossRef]

7. Florida, R. The Rise of the Creative Class: And How It's Transforming Work, Leisure, Community and Everyday Life; Basic Books: New York, NY, USA, 2002.

8. Fillis, I.; Rentschler, R. The Role of Creativity in Entrepreneurship. J. Enterp. Cult. 2010, 18, 49-81. [CrossRef]

9. Johansson, F. The Medici Effect: What Elephants and Epidemics Can Teach Us about Innovation; Harvard Business School Press: Boston, MA, USA, 2004.

10. Drucker, P. Innovation and Entrepreneurship: Practice and Principles; Harper and Row: New York, NY, USA, 1985.

11. Gosling, J.; Mintzberg, H. The Five Minds of a Manager. Harv. Bus. Rev. 2003, 81, 54-63. [PubMed]

12. Duening, T.N. Five Minds for the Entrepreneurial Future: Cognitive Skills as the Intellectual Foundation for Next Generation Entrepreneurship Curricula. J. Entrep. 2010, 19, 1-22. [CrossRef]

13. Mednick, S.A. The associative basis of the creative process. Psychol. Rev. 1962, 69, 220-232. [CrossRef] [PubMed]

14. Guilford, J.P. Traits of creativity. In Creativity and Its Cultivation; Harold, H.A., Ed.; Harper \& Row: New York, NY, USA, 1959; pp. 142-161.

15. Runco, M.A.; Acar, S. Divergent Thinking as an Indicator of Creative Potential. Creat. Res. J. 2012, $24,66-75$. [CrossRef]

16. Gibson, C.; Folley, B.S.; Park, S. Enhanced Divergent Thinking and Creativity in Musicians: A Behavioral and Near-Infrared Spectroscopy Study. Brain Cognit. 2009, 69, 162-169. [CrossRef] [PubMed]

17. Guilford, J.P. Creativity. Am. Psychol. 1950, 5, 444-454. [CrossRef] [PubMed]

18. Berg, C. Email correspondence. Fall 2013.

19. Sherrod, R.J. Discovering the Art of Guitar Fingering: A Comprehensive Text \& Study Guide; Alfred: Sherman Oaks, CA, USA, 1980.

20. Yates, S. J. S. Bach: Six Unaccompanied Cello Suites Arranged for Guitar; Mel Bay: St. Louis, MO, USA, 1998.

21. Koonce, F. (Ed.) The Solo Lute Works of Johann Sebastian Bach; Neil A. Kjos Music Company: San Diego, CA, USA, 2012.

22. Read, S.; Sarasvathy, S.; Dew, N.; Wiltbank, R. Effectual Entrepreneurship, 2nd ed.; Routledge: New York, NY, USA, 2017.

23. Amabile, T.M.; Hennesey, B.A.; Grossman, B.S. Social Influences on Creativity: The Effects of Contracted-for-Reward. J. Personal. Soc. Psychol. 1986, 50, 14-23. [CrossRef] 